\title{
WOMEN'S TIME AND THE USE OF HEALTH SERVICES
}

Joanne Leslie

A recent, detailed methodological review of time allocation research begins with the following key observation:

It can be argued that the fundamental scarce resource in the economy is the availability of human time, and that the allocation of time to various activities will ultimately determine the relative prices of goods and services, the growth path of real output, and the distribution of income.

(Juster and Stafford 1991:471)

'Concerns that time constraints, in particular time constraints of women, may be limiting the capacity of households to respond optimally to market incentives are increasingly being raised in analyses of the problems being encountered by countries undergoing the process of structural adjustment' (Joekes 1991). There are at least two ways that the constraints on women's time may be important determinants of the ability of households to respond to economics recession and/or structural adjustment policies. First, a deteriorating household financial situation puts pressure on women to join or to increase their participation in the paid labour force, of ten by adding a first or second job in the informal sector, since job opportunities in the formal sector, particularly for women, tend to be limited. At the same time, however, increased prices for essential goods and services combined with cutbacks in government supported social services put increased pressure on women to provide time intensive food preparation, health care, and other informal social support services, not only within their immediate households, but also within their extended kin groups and communities (Leslie, Lycette and Buvinic 1988).

The dual pressure on women's time has a range of important economic implications, as well as implications for the quality of women's lives. The specific issue with which this article is concerned, however, is the possible effect of time constraints on women's capacity to use health services or to engage in other health related activities. In an earlier paper, in which some of these ideas were first raised, I attempted to estimate the time requirements of utilization of the four principal child survival technologies - growth monitoring, oral rehydration therapy, breastfeeding, and immunization - within the context of the overall demands on women's time for market and household work. The paper also discussed the extent to which time costs may be a deterrent to the use of child survival technologies (Leslie 1989).
This article builds on and goes beyond the earlier analysis in two ways. First, the empirical base is expanded both by including more recent studies, and by considering a broader range of health interventions than just the four survival technologies. Second, an attempt is made to disaggregate health services and practices along a number of dimensions, with the goal of identifying those health related activities that may be particularly vulnerable to non-utilization because of conflicting demands on women's time. Both aspects of the article benefit from a thoughtful paper by Jeannine Coreil (1991).

One of the premises of the earlier paper was that, to the extent that the child survival technologies are essentially preventive in nature (although oral rehydration therapy may not be viewed as preventive by users) they will be considered to be discretionary by women, and/or other members of the household and therefore women's time constraints may be more of a deterrent to their use than to the use of acute or case management services. It is clear, however, from an examination not only of the limited number of studies of patterns of use of the child survival technologies, but also studies of the use of maternal health services, and family planning services (all of which are primarily targeted to women) that other factors interact with time costs in important ways to modify this simple distinction between preventive and management health care.

One key factor seems to be degree of flexibility in when time costs are incurred. In settings as different as the United States and Ethiopia, for example, critics of government health services have drawn attention to the problem of inconvenient clinic hours. Ayalew (1985) found that a major reason for the lack of success of health services in Ethiopia was the failure to understand and accommodate to normal patterns of women's time use in the community, and he recommended preparing a community time budget to help decide when and how services should be offered. In a similar vein, in proposing strategies to increase immunisation coverage in the US, Assistant Secretary of Health James $\mathrm{O}$. Mason observed, 'Our clinics aren't always open for the convenience of parents. We expect parents to adjust their schedules to fit ours - rather than the other way around. Immunization clinics should always be open on all workdays - during some non-working hours - and always during the hours that clinics are open' (The Nations Health, August 1991:9). 
One of the simplest reforms that could be made to increase health service usage and decrease inconvenience to women is extending clinic hours and/or keeping clinics open at times that are particularly easy for women to be away from home or employment.

A series of studies of analysing factors that influence the use of child health services in Haiti has led Coreil to conclude that household composition and age of child both interact in significant ways with the effect of maternal time demands (Coreil 1991). For example, she finds that it is the combined effects of maternal time constraints and the absence of alternate caretakers that limits the use of child health services, particularly services that must be used outside the home, such as immunization. In addition, she finds that the effects of maternal time constraints on use of child health services are stronger for infants than for older children, and in households with more children, which she attributes to the greater necessity of infants being accompanied to health clinics by their mothers, and the difficulty of doing this with other children to care for at the same time.

The cultural acceptability and/or quality of care of services may also interact in important ways with how willing women are to incur time costs. A review of research on utilization of formal (e.g. non-traditional) maternal nutrition and health care services in developing countries provides a number of examples of this (Leslie and Rao Gupta 1989). Because antenatal care is essentially a preventive service, whereas childbirth care is essentially an acute or management service, one might expect higher rates of utilization of formal childbirth services. However, just the opposite has been found. In countries where data on coverage of both antenatal and childbirth care are available, the percentage of women receiving antenatal care is almost invariably higher than the percentage of women attended by trained personnel during childbirth. The reasons for this appear to be twofold. First, where trained personnel are not available nearby or cannot go to a woman's home, the barriers presented by distance and lack of transportation are greater once labour has begun than they are earlier in the pregnancy (although they are also significant barriers to use of antenatal care). In addition, however, studies from a range of countries have found that a major barrier to use of formal childbirth services is the perception by women that clinics or hospitals will be unable to meet their needs for privacy, emotional support, and fulfilment of rituals to protect their own or their infant's health (see Finerman 1984, and other studies called in Leslie and Rao Gupta 1989).

From the perspective of the user, the difficulty with services that are provided away from home appears to be associated with not only their greater time costs but also the greater public exposure entailed by their use. This point is made both by Coreil (1991) in her analysis of determinants of use of child health services in Haiti, where she cites criticism about children's shabby appearance by health personnel as a source of acute embarrassment to mothers, and also by Bruce (1987) in her excellent critique of contraceptive technologies and family planning services from a feminist perspective. Bruce observes '. . . to the degree that obtaining a method entails a public visit to a contraceptive service, intimate discussions, and physical contact with nonfamily members, modern contraceptive technologies can threaten women in a way that traditional child spacing techniques do not. Extended breastfeeding, post-partum abstinence, withdrawal, diverse natural family planning systems are very private. The lack of curtains in an examining room, the unexplained and unnecessary presence of more than the examining physician or paramedic, and the lack of a separate interviewing room for taking reproductive histories are resented by women and may lead them to avoid services altogether.' (Bruce 1987:368).

My earlier paper on women's time and child survival technologies called attention to the surprising lack of research on the possible effect of women's time constraints on decisions relating to breastfeeding. One notable recent addition to this very limited literature, although focusing on an industrialized rather than on a developing country, is a study of a group of Canadian women's experience of breastfeeding [Maclean 1988]. While the study explores many aspects of women's experience of breastfeeding (both positive and negative), it reaches the following conclusion concerning the time demands of breastfeeding:

The first few months post-partum are very demanding on a woman's time. The mother is the primary caretaker of the baby and of any older siblings. Because she is nursing, she is solely responsible for the feeding activity. For many mothers in this study, the early months were characterized by frequent feedings and unpredictable feeding schedules. Evenings were hectic for a woman when, for example, an older child wanted to be fed, her husband came home and the baby was fussing. Often the baby wanted to nurse more frequently in the evenings. Nighttime feedings meant interrupted sleep and extreme fatigue. A woman could spend up to 12 hours per day nursing during the first 6-12 weeks of her baby's life (Maclean 1988:365).

Twelve hours per day may seem extreme to many readers, and undoubtedly represents an upper bound on the time demands of breastfeeding; however, it somewhat counterbalances the unrealistically low estimates of 50 to 116 minutes a day that have come from some earlier studies in developing countries (see 
Almroth et al 1979 and other studies cited in Leslie 1989). Direct evidence of a dramatic effect of breastfeeding on women's time allocation in a developing country setting comes from a recent study of the effects of reproductive status on women's time use in rural Kenya (Baksh, Neumann, Paolisso, Trostle and Jansen 1991). While time spent breastfeeding is grouped with holding, washing, feeding, etc. into child care time, rather than categorized as a separate activity, it is evident that the increase from 3.1 per cent of their time spent on child care in the last trimester of pregnancy to 23.2 per cent of their time spent on child care in the first three months postpartum is substantially attributable to breastfeeding. Overall, the authors calculate that the total decrease in women's work time during the six month period that includes the last trimester of pregnancy (when inactivity or rest time increases substantially) and the first three months of breastfeeding (when childcare time increases substantially) is 273 work hours, the equivalent of 1.5 hours per day or 25 eleven hour work days.

The issue of women's time constraints and breastfeeding warrants particular attention at this time, in light of recent recommendations by WHO and the US Agency for International Development that women in developing countries be strongly encouraged to practice exclusive breastfeeding for the first six months of their baby's life (Koniz-Booher, Fishman, Parlato and Roberts 1991). The time demands of exclusive breastfeeding are undoubtedly more intense than any other health service or health care practice targeted to women. Not only must breastfeeding be done daily, for several hours per day, but the interval between feedings cannot normally exceed four or five hours (unless a woman expresses and stores breastmilk). While breastfeeding has the convenience and privacy advantage of being a home based practice, as emphasized by Bruce above in discussing it as a family planning technology, not all women are able to be home based continuously throughout the day. Many aspects of both women's household and women's paid employment require women to be absent from home for several uninter rupted hours per day, and the extent to which infants can accompany their mothers during such activities shows great micro-regional variation. A study of female farmers in Western Nepal, for example, found that most women were unable to take infants to the fields with them, primarily because of the steep terrain and long distances to be travelled, but also because of fears about the infants' safety (Levine 1988).

The above analysis leads to a somewhat more complex set of hypotheses about the effects of women's time constraints on the use of health services than those hypothesized in my earlier paper (Leslie 1989). Coreil (1991) has proposed that research on participation in health related activities in general, and on the effects of women's time contraints in particular, be disaggregated along two dimensions, which she identifies as the setting or domain in which the care takes place, and the level of care. In addition to these two dimensions, I would propose that a third important dimension is whether the activity must be carried out by the mother or woman herself, or can be carried out by someone else. A matrix incorporating these three dimensions is shown in Figure 1, which also includes examples of one or more health related behaviours that would fall into each category.

Following the matrix in Figure 1, and based on the limited empirical evidence to date, I would hypothesize that women's time constraints would more powerfully affect utilization of preventive than management care, would more powerfully affect utilization of clinic or hospital based services than health related practices in the home, and would more powerfully affect activities that must be carried out by women themselves than those that can be carried out either by the women/mother or by someone else. The total demands on women's time, as well as the cultural appropriateness, quality, and convenience of services or recommended practices will modify these broad tendencies and, thus, would lead one to expect significant micro-regional variation. I would end by reiterating the conclusion of the earlier paper, that more studies are urgently needed, both to quantify the actual time costs associated with different health related activities, and, of even greater importance, to begin to establish the significance of these time costs relative to other determinants of use of health services, or implementation of home based health practices.

\footnotetext{
This updated material was written as a follow-up to the IDS Bullerin Workshop on Gender and Health: Issue for the Coming Decade. It builds on an earlier extensive analysis of women's time as a key factor in the use of child survival technologies (Leslie 1989).

The earlier paper synthesized findings from 27 time allocation studies showing that woman in developing countries face severe time constraints. It was noted that such studies give a less clear picture of the time women spend on health and child care in the home and utilization of health services, however, because these are primarily sporadic, not daily, activities. One clear implication is that reporting time spent by women on illness or health care utilization as a daily average masks the true cost to women of periodically losing half of a day or more of work time.
}

The earlier paper found that almost no direct empirical data have been gathered on the time costs to women of breastfeeding, immunizations, oral rehydration therapy, or growth monitoring, nor on whether time costs are an important determinant of utilization of these technologies. Specific research designed around the introduction of child survival proiects, plus the inclusion of appropriate measures in the evaluations of ongoing projects, could fill this gap. Even without further research the earlier paper concludes, recognition of the time constraints faced by low-income mothers in conjunction with lessons learned from successful growth monitoring and immunization projects suggests that out reach efforts may be an important key to increasing utilization of child survival technologies. 
Figure 1: Illustrative matrix of health services and practices by location, user, and type

\begin{tabular}{|c|c|c|c|}
\hline Location & User & Preventive & Management \\
\hline \multirow[t]{3}{*}{ Home } & Mother only & $\begin{array}{l}\text { Breastfeeding } \\
\text { Ante-natal self-care }\end{array}$ & $\begin{array}{l}\text { TBA or family-assisted } \\
\text { childbirth }\end{array}$ \\
\hline & \multirow[t]{2}{*}{$\begin{array}{l}\text { Mother or other } \\
\text { member of household }\end{array}$} & $\begin{array}{l}\text { Natural family } \\
\text { planning and barrier } \\
\text { contraceptives }\end{array}$ & $\begin{array}{l}\text { Oral rehydration } \\
\text { therapy }\end{array}$ \\
\hline & & $\begin{array}{l}\text { Preparation of } \\
\text { enriched weaning } \\
\text { foods }\end{array}$ & $\begin{array}{l}\text { Care and feeding of } \\
\text { 'bedridden' members } \\
\text { of household }\end{array}$ \\
\hline & Mother only & $\begin{array}{l}\text { Ante-natal exam } \\
\text { Tetanus toxoid }\end{array}$ & $\begin{array}{l}\text { Abortion } \\
\text { Midwife, nurse, physician } \\
\text { assisted childbirth }\end{array}$ \\
\hline \multirow{3}{*}{$\begin{array}{l}\text { Health post } \\
\text { or clinic }\end{array}$} & \multirow{3}{*}{$\begin{array}{l}\text { Mother or other } \\
\text { member of household }\end{array}$} & Growth monitoring & Antibiotics \\
\hline & & Child immunization & Antihelmentics \\
\hline & & $\begin{array}{l}\text { Most non-barrier } \\
\text { contraceptives }\end{array}$ & Quinine \\
\hline
\end{tabular}

\section{REFERENCES}

Almroth, S., Greiner, T., and Latham, M. C., 1979, 'Economic importance of breastfeeding'. Food and Nutrition, Vol 5 No 2: 4-10

Ayalew, S., 1985, 'Time budget analysis as a tool for PHC planning (with examples from Ethiopia)', Social Science and Medicine, Vol 21 No 8: 865-872

Baksh, M., Neumann, C., Paolissa, M., Trostle, R., and Jansen, A. A. J., 1991, 'The influence of reproductive status on rural Kenyan women's time use', School of Public Health, University of California, Los Angeles

Bruce, J., 1987, 'Users' perspective on contraceptive technology and delivery systems - highlighing some feminist issues', Technologv in Society, Vol 9: 359-83

Coreil, J., 1991, 'Maternal time allocation in relation to kind and domain of primary health care', Medical Anthropology Quarterly, Vol 5 No 3: 221-235

Finerman, R., 1984, 'A matter of life and death: health care change in an Andean community', Social Science and Medicine, Vol 18 No 4: $329-34$

Joekes, S., 1991, 'Women and structural adjustment: operational implications for the JCGP member agencies', IDS, Sussex, May
Juster, F. T. and Stafford, F. P., 1991, 'The allocation of time: empirical findings, behavioral models, and problems of measurement', fournal of Economic Literature, Vol 29: 471-522

Koniz-Booher, P., Fishman, C., Parlato, M., and Roberts, A., 1991, 'Recommendations from the expert meeting on “Optimal Infant Feeding Practices' September 24-25, 1990', Academy for Educational Development, Washington, DC

Leslie, J., 1989, 'Women's time: a factor in the use of child survival technologies?', Health Policy and Planning, Vol 4 No 1: 1-16

-and Rao Gupta, G., 1989, 'Utilization of formal services for maternal nutrition and health care', International Center for Research on Women, Washington DC, February

-Lycette, M., and Buvinic, M., 1988, 'Weathering economic crises: the crucial role of women in health', in Bell, D. E. and M. R. Reich (eds.), Health, Nutrition, and Economic Crises Approaches to Policy in the Third World, Auburn House Publishing Company, Dover, Massachusetts

Levine, N. E., 1988, 'Women's work and infant feeding: a case from rural Nepal', Ethnologv, Vol 27 No 3: 231-51

Maclean, H. M., 1988, 'Women's experience of breastfeeding: a much needed perspective', Health Promotion, Vol 3 No 4: $361-70$ 